\title{
Los periódicos en crisis (II): Las lecciones de Kennedy
}

La clave de la futura prensa escrita es la integración del equipo que la produce. No se obtendrán buenos resultados

si un director se asombra o se irrita cada vez que le mencionen la palabra marketing; tampoco si el gerente no comprende el trabajo de los periodistas y la función social que ellos desarrollan.

Ése fue uno de los puntos que más destacó el profesor

George Kennedy — de la Escuela de Periodismo de la Universidad de Missouri-Columbia- en su visita a Chile. Invitado por la Escuela de Periodismo de la Universidad Católica, dictó la conferencia La batalla de los gerentes y directores de diarios en Estados Unidos para ganar nuevos

lectores y anunciantes, ante académicos, alumnos, ejecutivos y directores de medios del país. Luego contestó preguntas sobre problemas específicos de la prensa chilena.

A continuación ofrecemos parte de la conferencia y un resumen de lo más relevante del diálogo: 
H ace diez años, la idea de que sería necesario librar una "batalla" para conseguir nuevos lectores y conservar los que se tenían parecía un mal sueño. Pero hoy los gerentes, los directores e incluso algunos profesores saben que eso es, precisamente, lo que ha sucedido.

La industria de la prensa escrita ha pasado de una situación muy confortable, en la que tanto los anunciantes como los lectores necesitaban del periódico, a otra menos confortable en la que el periódico debe demostrar su valor a ambos; y además, día a día.

Los datos en Estados Unidos son claros y preocupantes:

- La circulación diaria es de $63 \mathrm{mi}$ llones; hace 20 años era de 62.

- El número de ejemplares vendidos por cada cien personas ha caído del 46 por ciento al 35 por ciento.

- Y, como consecuencia, el crecimiento de la publicidad es muy lento.

En 1987 los periódicos tenían el 26,8 por ciento de toda la publicidad; en el 88 , el 26,3 . Por supuesto, estos porcentajes todavía son superiores a las inversiones en televisión o publicidad directa, pero esos están creciendo.

En definitiva, nos encontramos con una industria muy poderosa, muy rentable pero muy preocupada.

Las asociaciones de editores y directores (ANPA Y ASNE) y el Newspaper Advertising Bureau llegaron a la conclusión de que la clave está en la conquista de nuevos lectores. Los anunciantes siguen siempre a los lectores.

Pero como ustedes saben bien, es más fácil decirlo que hacerlo. Para ganarlos, es necesario descubrir por qué se han perdido. Muchas investigaciones nos dan algunas razones, pero ninguna ofrece datos concluyentes. Lo cierto es que hace 20 años el el 78 por ciento decía haber leído un diario el día anterior. Y en 1988 ,

\section{"Ya no es suficiente, si alguna vez lo fue, publicar lo que se quiere y forzar al lector a tragárselo. Ahora él tiene demasiado donde elegir»}

el porcentaje bajó al 74.

La razón fundamental parece consistir en que millones de personas que pueden leer no quieren leer periódicos. La pregunta es ¿por qué?

En los sondeos y en las entrevistas, estas personas dicen que entienden la importancia del periodismo; que leen un diario de vez en cuando, quizás un día a la semana. Pero que un periódico no es necesario en sus vidas.

Existen otras demandas de los lectores que los periódicos intentan satisfacer. Quieren noticias breves y muy locales. Por eso los periódicos, aún los grandes, publican ahora columnas de obituarios, todos los que se divorcian y se casan, etc. La frase "los nombres propios hacen noticias" es muy vieja pero sigue siendo nueva.
Noticias pequeñas y noticias grandes. El reportaje de investigación no ha muerto y el reportaje de análisis progresa. Se usan los ordenadores personales, no sólo como máquinas de escribir, sino también para analizar estadísticas. Las escuelas de periodismo ahora enseñan estadísticas, aunque esto no alegre precisamente a los alumnos.

Desde el año ochenta y tres, el setenta y nueve por ciento de los diarios ha cambiado sus contenidos. El ochenta y dos por ciento ha cambiado su diseño o ha añadido gráficos.

Para uno de los más importantes grupos de no lectores, la utilidad no es suficiente. Los jóvenes quieren diarios con viveza, y ellos son los lectores de los años noventa. Para ellos el periódico deber ser a la vez útil, fácil de usar y también interesante.

"No necesitamos ser tan aburridos", dice Jennie Buckner, vicepresidenta de información del Knight-Ridder. "Podemos proscribir el aburrimiento", añade.

Proscribir el aburrimiento implica gráficos en color, artículos no demasiado largos, escritos con estilo, y sobre todo, temas interesantes.

¿Cuáles son estos temas? Buckner, por ejemplo, señala los que siguen:

- Psicología: "Nada interesa más a la gente que la gente", según ella. Muchas personas, especialmente las mujeres, quieren leer sobre los problemas cotidianos y sus soluciones.

- Trabajo: No sólo las estadísticas de empleo, como de costumbre, sino también la vida de la gente en el mercado, en la fábrica, en el rancho.

- Tecnología: El computador cambia el estilo de trabajo y de vida. Los periódicos viven esos cambios, pero habitualmente no escriben sobre ellos. ¿Qué significa esta era informática para la gente de a pie? Si el diario no nos lo dice, ¿quién lo hará? 
- La familia: Los políticos conocen su importancia, pero los periodistas no explican cómo los intereses tecnológicos, económicos y demás cambian la familia y la amenazan.

- Etica: Hay muchas preguntas importantes. Desde el aborto a la honradez. El periódico que quiera ganar la atención de los jóvenes debe escribir sobre tales preguntas.

- La tercera edad: Los viejos serán la carga de los jóvenes y los ancianos son nuestros lectores más leales. Los periódicos deben preocuparse de los lectores dice, Buckner.

Y, dice Virgil Fassio, editor de Seattle Post-Intelligencer, "la circulación es la sangre que da vida a un periódico". Hasta ahora, he hablado sólo de un tema: La calidad del periodismo. Es el tema más importante cuando los directores y gerentes se reúnen. En realidad algunos gerentes dicen que hoy en día es necesario invertir en calidad aunque suponga menos rentabilidad a corto plazo.

Uno de ellos, Tom Guiffrida, del The Palm Beach Post, dijo a la Federación Internacional de Editores de Periódicos que su diario redujo las ganancias durante dos años para invertir en calidad. Aumentó la redacción en un veinte por ciento, las columnas para noticias, y rediseñó el diario.

Como consecuencia, la circulación subió cerca del veinte por ciento y los beneficios han mejorado. Más aun, el futuro está asegurado.

La lección de Florida parece bastante clara: para asegurar su futuro: lo mejor es invertir en calidad.

Pero deseo comentar brevemente otro tema: para muchos de los editores y directores más progresivos -incluidos los de The New York Times, Los Angeles Times y Knight-Ridder - no basta con hacer mejor lo habitual. Para asegurar el futuro, los periódicos deben asimismo redefinir las noticias.

Como ya he dicho, muchos de los no lectores, jóvenes incluidos, creen que el contenido del periódico es inútil y aburrido. Entonces, como Jennie Buckner, los directores buscan noticias nuevas o nuevas vías para presentarles.

Este movimiento se llama Nuevas direcciones para las noticias. Como su nombre, el movimiento es nuevo. La idea consiste en preguntar a personas con imaginación —periodistas o no, mejor si no lo son- por dónde discurrirán las noticias importantes del futuro: las de mañana y las del próximo año. Las tendencias, las corrientes sociales, los temas casi invisibles.

También los diseñadores hacen sus intentos.Al final quizá resulten periódicos totalmente nuevos. Lo importante es que nuestra industria ha aprendido una gran lección: que los lectores son más necesarios a los periódicos que éstos a los lectores.

Con esta lección, se han alcanzado también algunas mejoras muy prácticas y útiles que los periódicos pueden emplear para ganar lectores y para satisfacer a los lectores actuales. Algunas sugerencias:

- Dar informaciones útiles. Como por ejemplo, las atracciones del fin de se- mana, guías de los supermercados o sugerencias para renovar el jardín. La clave radica en que sean útiles al lector y no simplemente fáciles de elaborar.

- Explicar los sucesos, los datos. Y explicar el periódico mismo. La gente quiere y necesita entender las cosas que le afectan. Por ejemplo, The Daily News of Filadelphia publica una columna que se llama "El lector que sabe", con la que intenta explicar las noticias de un modo sencillo, accesible a los que no leen bien.

- Demostrar interés por lo local. Se puede conseguir con una página o con una sección dedicada a noticias de un barrio. O con artículos que expliquen los efectos de algún acuerdo entre las empresas y trabajadores locales. En los Estados Unidos se dice que todas las noticias son locales.

- Diseñar muchos puntos de entrada. La primera página, especialmente y también las demás, deben incluir gráficos, dibujos y titulares con viveza, con fuerza. No sensacionalista, sino interesante. Es importante, tanto para los periodistas como para los anunciantes, que el mayor número posible de los que ven el periódico también lo lean.

- Ofrecer una sección de "breves de lectura rápida" (quick read), para aquellos que no tienen más que unos pocos minutos. Gráficos como los de USA Today también ayudan. Una columna de noticias breves, telegráficas, puede llegar a ser popular.

- Publicar más buenas noticias. La vida no es sólo crimen, desastre y política. Pero en el periódico, a veces parece que sí. Los chistes no son necesarios, pero historias sobre personas buenas que hacen cosas buenas sí ló son.

- Proporcionar algunos "artículos que se deben leer". Son los que la gente discu- 
te en el café y los que los otros medios no tienen: investigaciones sobre temas locales, o reportajes menos serios, pero interesantes, como un perfil de personalidad o la narración de algún suceso extraño.

Muchas gracias.

-En Chile hay una experiencia especial respecto a una forma de captar nuevos lectores y que en un primer momento tuvo éxito: las revistas han regalado libros, primero, luego casetes y otro tipo de cosas. ¿Cuál es su opinión, como periodista, sobre esta forma de atraer público?

-Los periódicos, en general, deberían ser una empresa dedicada a ganar dinero y no a regalarlo. A la larga, es mucho más efectivo publicar periódicos, ya sea semanal o diariamente, cuyo contenido tenga valor en vez de depender de trucos. En Estados Unidos hemos hecho y visto muchos intentos de ese tipo y el problema es que, al final, la gente se cansa de eso y se pierden los lectores que se han ganado. Y tanto los periodistas como los publicistas terminan sintiéndose engañados.

- ¿Ha sido la crisis de lectores un factor determinante para que los diarios se parezcan cada vez más a las revistas como Time o Newsweek?

-Sí, de hecho eso ya está sucediendo y por ello hay muchos en Estados Unidos que piensan que el futuro de la revistas de actualidad no es muy prometedor. Los periódicos están proporcionando cada vez más análisis, investigaciones e información especializada. Y ése solía ser el campo de las revistas. Si hoy leo The Miami Herald, The Philadelphia Inquirer o The Saint Louis Post Dispatch, no estoy seguro de si necesito revistas como Time o Newsweek. Y los publicistas están sintiendo esto también: USA Today ve su competencia para la publicidad más en la revistas de noticias que en los mismos diarios.

- ¿Y qué están haciendo las revistas frente a esta situación?

- Creo que la industria de las revistas se está yendo hacia dos direcciones muy claras: una es la llamada "periodismo de servicio", es decir, revistas para dueñas de casa, deportistas, fanáticos del automóvil, etc. La otra es un tipo de periodismo muy tradicional que está reapareciendo: la

Me parece que se
puede aplicar un
principio general a
todos los países y
ése es que el
periodismo,
especialmente en el
diario, es una
manera en que la
sociedad moderna
lleva una
conversación
consigo misma

revista de ideas. The New York Republic, The Washington Monthly, The New Yorker son unas de las publicaciones con más éxito y más valiosas en la actualidad $\mathrm{y}$ tienen un precio en el mercado que les asegura lectores y gente que quiere publicar ahí sus anuncios.

- Teniendo en cuenta que acá se da la misma guerra por ganar más lectores, ¿cree que ese cambio del que usted habla puede aplicarse en Chile o en otros países latinoamericanos cuyos periódicos están siendo o han sido copiados en cierta manera de las grandes capitales?

- Me parece que se puede aplicar un principio general a todos los países y ése es que el periodismo, especialmente en el diario, es una manera en que la sociedad moderna lleva una conversación consigo misma. Por lo tanto, la fórmula que puede ser perfecta en una sociedad puede ser totalmente irrelevante en otra. La lección que finalmente los directores de medios norteamericanos están aprendiendo bajo la presión económica —que parece ser la única manera en que los editores aprenden cualquier cosa- es que es realmente necesario poner atención a los deseos de los lectores, porque ya no es suficiente, si alguna vez lo fue, publicar lo que se quiere y forzar al lector a tragárselo. Ahora él tiene demasiado donde elegir.

-Hay algo que para los ingenieros comerciales es bastante sabido: la empresa que no se mete en el marketing está perdida. Por eso mismo, ¿por qué cree usted que los periodistas se demoran tanto en aprender una cosa que aparentemente es de sentido común: mi negocio resulta si la gente a la cual yo pretendo satisfacer está satisfecha?

- i¿Quién conoce la mente de un

Cuadernos de Información №6, 1990 
periodista?! Creo que los periodistas en general se creen más artistas que hombres de negocio. Si hubieran querido ser esto último habrían estudiado Ingeniería. Pero ahora se están dando cuenta de que la palabra clave es marketing, les guste o no. Porque la industria de la prensa escrita al menos en Estados Unidos- es hoy todavía muy rentable, pero un poco más allá en el horizonte se ven señales de alarma.

- $^{-}$Cree que esto del periodistaartista o periodista-soñador es un problema de formación de las universidades donde se aprende esta profesión?

—Sí, en cierta forma. Las escuelas de periodismo en Estados Unidos han empezado recién a poner atención a la parte económica. Tengo entendido que en esta escuela (de Periodismo de la U.C.) se está dando un nuevo curso de Empresa periodística y ahora en la mía y en otras enseñamos eso, pero hace diez años no se hacía. La parte de negocios era función del departamento de publicidad, del departamento de circulación, del gerente. Sólo ahora hemos aprendido que los redactores sin lectores son inútiles $\mathrm{y}$, a la larga, estarán cesantes.

- ¿Quiénes están hoy día en la dirección superior de las empresas informativas norteamericanas? ¿Son periodistas, gente del marketing, o grandes empresarios?

-En este momento casi todos los gerentes son hombres de negocio y no periodistas. Creo que esa situación está empezando a cambiar ya que se dieron cuenta de que el negocio es, de hecho, el periodismo; no basta con ser un buen manipulador de dinero o un experto de la parte técnica porque a la larga todo eso queda en nada, si uno no está publicando algo que la gente realmente quiera leer. Grandes cadenas en Estados Unidos como The New York Times y otros grupos están desarrollando periodistas para que se conviertan en gerentes, entrenándolos en finanzas, administración y asuntos de

\section{«Estoy de acuerdo en que muchas veces los periodistas ponen demasiada atención a la opinión de sus colegas y no la suficiente al público»}

negocio en general. Pienso que es muy buen signo y me hacen pensar con optimismo sobre el futuro de mi oficio.

- Hace veinte o treinta años, quien dirigía un diario o una revista era una especie de artista, barómetro político o cientista social. Si se pudiera hacer hoy un perfil del buen director de una empresa informativa, ¿cuál cree usted que serían algunas características que no le pueden faltar?

-Primero: ser un buen periodista. Segundo: habilidad para dirigir, para inspirar a los reporteros y a los subdirectores para llevar a cabo esta misión. Tercero: una sólida comprensión de la economía: ¿Cuánto cuesta añadir dos páginas al diario? ¿Qué significa ganar o perder diez mil lectores? Hace cinco años muy pocos directores sabían o se preocupaban de tales problemas. Ahora muy pocos pueden permitirse el lujo de no saber, porque la gente que está en el lado comercial, y que puede no simpatizar mucho con el periodismo, siempre ganará las luchas internas.

- ¿Significa eso, al revés, que las personas encargadas de la parte comercial deberían también estar impregnadas del conocimiento de lo que es periodismo?

- Un antiguo y famoso periodista en Estados Unidos dijo una vez: "Todo lo que necesito de mi gerente es que fabrique plata". Pero para hacer dinero, sobre todo ahora, se necesita primero crear y luego vender un periodismo de alta calidad. Por eso, de aquí a diez años, dudo que en Estados Unidos haya muchos gerentes de éxito que carezcan de una sólida comprensión de lo que es el periodismo.

-Cuando los periodistas dicen "periodismo de calidad" eso tiene sentido para mí, como gerente, si se asume que la calidad la mide el lector. Si un redactor se siente contento una vez que ha hecho su texto se lo muestra al director y éste le dice que sí, hasta ahí no ha ganado la batalla; la batalla está ganada cuando la gente lee y le gusta el artículo. Pero cuando converso con algunos periodistas y hablamos de la calidad, me da la impresión de que ellos tienden a pensar en algo parecido a la industria de relojes suiza: Nadie duda de que un reloj suizo es de buena calidad, pero este concepto, desde el punto de vista de los consumidores, cambia. $Y$ hoy la relojería suiza está, en términos de venta y sucursales en el mundo, en el suelo. Lo que la gente quiere ahora es un reloj barato, pero que funcione tan bien como uno suizo... 


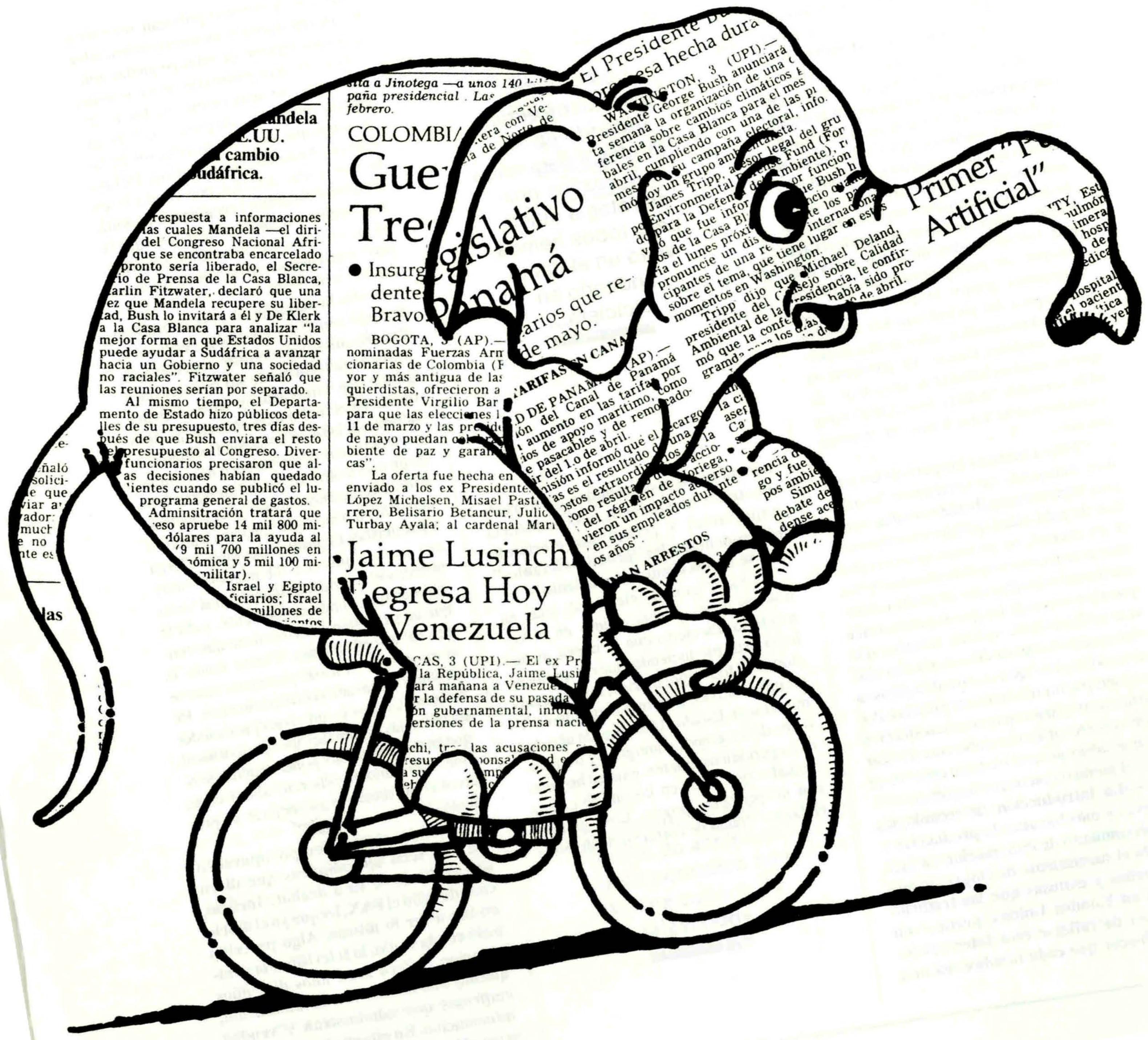


- Creo que la pregunta que habría que hacerse es: ¿qué clase de relojes quiero vender y a quiénes? El público de The New York Times no es el mismo del USA Today. Muchos de los artículos que el The New York Times publica en gran tamaño merecen apenas unos párrafos o un gráfico en USA Today. Pero estoy de acuerdo con ustedes en que muchas veces los periodistas ponen demasiada atención a la opinión de sus colegas y no la suficiente al público. Ahora en Estados Unidos nosotros estamos usando cada vez más encuestas científicas para descubrir lo que la gente quiere o al menos dice que quiere y luego, lo que realmente lee. Creo que los resultados de estas encuestas deberían ser muy prometedores para los periodistas, porque lo que la gente dice que espera del periodismo son artículos serios y bien escritos, interesantes, importantes, noticias locales. El problema es que en muchos casos la definición que da el lector sobre "noticia importante" no es exactamente la misma que da el periodismo.

"Muy a menudo los periodistas estamos trabajando de secretarios de actas para organismos gubernamentales, agencias de publicidad, políticos o empresas. $\mathrm{Y}$ en general, no creemos que esto produzca artículos muy interesantes y las encuestas muestran que el público tampoco los necesita. Lo que el público cree que es interesante son los artículos que realmente afectan su vida diaria. No sólo esos artículos que están dirigidos a alguien por un relacionador público. Por lo tanto, me parece que, si somos sinceros con nosotros mismos, deberíamos hacer lo que sabemos; está bastante cerca de lo que el público quiere que hagamos.

- La introducción de tecnologías nuevas y más baratas, la producción y procesamiento de información ha facilitado el surgimiento de empresas más pequeñas y exitosas que las tradicionales en Estados Unidos, porque son capaces de reflejar esos intereses locales, hacer que cada hombre sea una

\section{Los grandes periódicos están tratando de ser grandes y pequeños \\ a la vez; es una estrategia difícil, pero todos hemos visto un elefante andando en bicicleta...}

noticia en las comunidades. ¿Hay realmente un movimiento, una tendencia importante? Y ¿cómo está afectando esa tendencia a los "grandes elefantes" que se mueven mucho más lento?

-Esos "grandes elefantes" están en muchos casos encontrándose en el cementerio. Es cierto que la nueva tecnología está produciendo nuevas publicaciones de todo tipo: diarios, revistas, cartas informativas, informes particulares. $Y$ mientras en Estados Unidos cada año dos o tres de los grandes, antiguos y tradicionales periódicos mueren, existen hoy más ciudades que antes en las que se cuenta con un periódico propio. Los "grandes elefantes" tratan de competir de diversas maneras. A menudo publican secciones locales para áreas o sectores residenciales privados repletas de estas pequeñas noticias, retratos de gente común y corriente, anuncios de matrimonios, listas de graduaciones de colegios, nombres de personas que han ganado ascensos en las Fuerzas Armadas o en el trabajo. Incluso hechos como arrestos por conducir en estado de ebriedad. Los grandes periódicos están tratando de ser grandes y pequeños a la vez; es una estrategia difícil, pero todos hemos visto un elefante andando en bicicleta...

-En la pequeña empresa donde yo trabajo muchas veces la gerencia o el departamento de ventas esperan que uno ponga noticias de sus clientes para ganar los contratos y uno siempre queda en el limbo del conflicto. ¿Cómo se maneja esto en Estados Unidos?

-Algunas cosas parecen no cambiar de un país a otro. Hay muchos periódicos e incluso muchas más revistas pequeñas que venden o entregan espacios a amigos y publicistas. El problema es que a la larga esa es una política de negocios muy pobre; y el argumento que algunas veces gana es que, fundamentalmente, todo lo que un periódico o revista tiene que vender es su credibilidad. Por lo tanto, la empresa que fracase periodísticamente también fracasará económicamente. En Estados Unidos es un signo prometedor que muchas organizaciones periodísticas que acostumbran no poner mucha atención a la calidad editorial, ahora están invirtiendo dinero para mejorar el producto.

- Cada cierto tiempo aparecen algunas tesis apocalípticas que dicen que el diario se va a acabar. Incluso, cuando salió el FAX, leí que ya el diario no iba a ser lo mismo. Algo parecido pasó con la radio, la televisión, la computación... Pero hará unos diez años que hay una tendencia a las multimedia, empresas que administran $y$ venden información. En este contexto, el diario sería sólo una manera de distribuirla. 
Una investigadora me dijo además que el diario era la forma más tonta porque es la más cara..

-Mi experiencia es que los investigadores dicen muchas tonterías. Creo que quien afirma que el diario está muerto o está muriendo, es una persona que no está poniendo mucha atención a lo que está pasando en el mundo. El FAX se desarrolló en forma experimental en los años cuarenta y con seguridad mucha gente dijo entonces que ése era el futuro. Bueno, sí, pero como un nuevo medio de comunicación especializado, no como un sustituto del diario. Hay diversos cambios pero creo que los periódicos, en forma muy similar a la actual, estarán con nosotros por mucho tiempo.

"Hay dos razones para esto: los lectores y los publicistas. Creo que se ha demostrado en forma concluyente que muy poca gente quiere ver las noticias escritas en una pantalla de televisión. Se ha demostrado también que a mucha gente le gusta el tipo de selección y los paquetes de información que da un periódico y que ningún otro medio de comunicación puede dar. Para los publicistas, en Estados Unidos, los tipos de avisos más importantes, aquéllos de ventas al detalle de los supermercados y las grandes tiendas, no pueden ser bien hechos por la televisión, por computador $\mathrm{u}$ otro medio, tan especialmente eficaz como las palabras impresas en un papel accesible en un quiosco o repartido a domicilio.

"Creo que lo que veremos pronto será que la gente que desee más información especializada que la que los diarios pueden ofrecer, podrá comprarla en

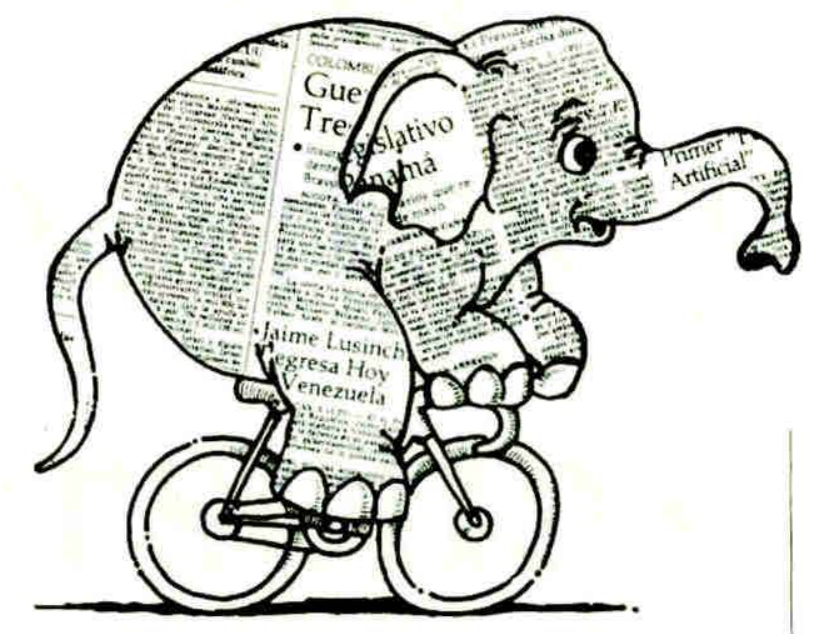

forma separada, probablemente por computación. Por ejemplo, en Monterrey, México, el diario El Norte desarrolló mediante su propio sistema computacional un banco de datos estadísticos de todo tipo: negocios, gobierno, bienes raíces, economía, etc. Algunos de los editores publicaron estos datos, pero muchos eran vendidos a clientes que pagan un derecho y luego conectan su propio computador al del periódico. Así, cada quien comprará tanta información, en profundidad y detalle, como desee.

"Creo que el futuro de los periódicos en mi país es probablemente más prometedor que el futuro de las grandes cadenas de televisión. Preferiría ser dueño de acciones de un periódico que de una cadena de televisión".

\section{- ¿Por qué tan drásticamente?}

-Porque el público de televisión se ha dividido una y otra vez hasta el punto que las grandes cadenas e incluso las estaciones privadas están perdiendo público. Hace diez años existían tres canales de televisión, en cambio ahora hay 28 y en la mayoría de las ciudades mucho más de uno. Por lo tanto, los periódicos tienen la verdadera posibilidad de convertirse nuevamente en lo que una vez fueron: el verdadero y mejor medio de comunicación, la manera más eficaz para que los publicistas lleguen a la gente con posibilidades de compra. Mi única desconfianza se basa en que los dueños de periódicos norteamericanos han demostrado, a través de los años, tener una gran capacidad para tomar decisiones estúpidas. Es posible que hoy no logren aprender las lecciones necesarias y quizás tropiecen con los cementerios de elefantes. 